\title{
POLYCLONAL OUTBREAK OF BLOODSTREAM INFECTIONS CAUSED BY Burkholderia cepacia COMPLEX IN HEMATOLOGY AND BONE MARROW TRANSPLANT OUTPATIENT UNITS
}

\author{
Icaro BOSZCZOWSKI(1), Gladys Villas Boas do PRADO(1), Mirian F. DALBEN(1), Roberto C. P. TELLES(2), Maristela Pinheiro FREIRE(1), \\ Thaís GUIMARÃES(1), Maura S. OLIVEIRA(1), Juliana F. ROSA(2), Robson E. SOARES(2,3), Pedro Enrique Dorlhiac LLACER(4), \\ Frederico Luiz DULLEY(5), Silvia F. COSTA(2) \& Anna S. LEVIN(1,2)
}

\begin{abstract}
SUMMARY
Aim: The objective was to describe an outbreak of bloodstream infections by Burkholderia cepacia complex (Bcc) in bone marrow transplant and hematology outpatients. Methods: On February 15, 2008 a Bcc outbreak was suspected. 24 cases were identified. Demographic and clinical data were evaluated. Environment and healthcare workers' (HCW) hands were cultured. Species were determined and typed. Reinforcement of hand hygiene, central venous catheter (CVC) care, infusion therapy, and maintenance of laminar flow cabinet were undertaken. 16 different HCWs had cared for the CVCs. Multi-dose heparin and saline were prepared on counter common to both units. Findings: 14 patients had B. multivorans (one patient had also B. cenopacia), six non-multivorans Bcc and one did not belong to Bcc. Clone A B. multivorans occurred in 12 patients (from Hematology); in 10 their CVC had been used on February 11/12. Environmental and HCW cultures were negative. All patients were treated with meropenem, and ceftazidime locktherapy. Eight patients (30\%) were hospitalized. No deaths occurred. After control measures (multidose vial for single patient; CVC lock with ceftazidime; cleaning of laminar flow cabinet; hand hygiene improvement; use of cabinet to store prepared medication), no new cases occurred. Conclusions: This polyclonal outbreak may be explained by a common source containing multiple species of Bcc, maybe the laminar flow cabinet common to both units. There may have been contamination by B. multivorans (clone A) of multi-dose vials.
\end{abstract}

KEYWORDS: Burkholderia cepacia complex; Bloodstream infection; Nosocomial infection; Hematology; Bone marrow transplant.

\section{INTRODUCTION}

Burkholderia cepacia complex (Bcc) comprises at least 15 different species or genomovars based on phenotypic and genotypic analyses ${ }^{16,17}$. Identification to species level has been troublesome in the clinical laboratory. Automated methods seem to perform poorly in identifying species of $\mathrm{Bcc}^{19,25}$. Molecular methods are more appropriate ${ }^{8,12,16}$. Clinically, Bcc mainly cenocepacia and multivorans species are important colonizers and cause respiratory tract illness among cystic fibrosis patients $^{1}$. In the hospital, the importance of Bcc is due to its potential to spread from person to person and to survive in moist environments. Multiple healthcare-associated outbreaks have been described involving contaminated water ${ }^{11}$, prefabricated moist washcloths ${ }^{13}$, contaminated medication $^{14}$, nebulization solution ${ }^{15}$, antiseptic solution ${ }^{9}$, heparin ${ }^{24}$, moisturizing body milk $^{2}$, mouthwash solution ${ }^{1}$. We report here an outbreak involving different species of Bcc and the dissemination of a predominant clone suggesting heavy contamination by a common source.

\section{METHODS}

The outbreak occurred in Hospital das Clínicas, a 2000-bed hospital affiliated to the University of São Paulo, during the period from January 1 to February 29, 2008. The hospital is divided into six institutes and transfer of patients between institutes occurs. The outbreak involved two outpatient units: one for patients with hematological malignancies and the other for bone marrow transplant patients. These units were adjacent and independent but shared one room which contained a laminar flow cabinet used to prepare chemotherapy and a counter used to prepare intravenous medication. In these units, the patients were admitted for a few hours at a time and received medication including intravenous therapy such as chemotherapy, antimicrobial drugs and hydration through central venous catheters.

The outbreak of bacteremia caused by B. cepacia was suspected on February 15, 2008 and an investigation was triggered. A case was defined as a patient with B. cepacia bacteremia occurring in January or February, 2008 who received care or medication prepared in these units. An evaluation of all positive blood cultures in patients hospitalized in the entire hospital during these two months and during the previous 12 months was also undertaken. Visits to both affected outpatient units were made for evaluation.

The hospital records of all case patients were evaluated and the

(1) Infection Control Department, Hospital das Clinicas, Universidade de São Paulo, SP, Brazil.

(2) Department of Infectious Diseases and LIM-54, University of São Paulo, São Paulo, SP, Brazil.

(3) Pontifícia Universidade Católica de São Paulo, Brazil.

(4) Hematology Unit, Hospital das Clínicas, University of São Paulo, São Paulo, SP, Brazil

(5) Chief of Bone Marrow Transplant Unit, Hospital das Clínicas, University of São Paulo, São Paulo, SP, Brazil.

Correspondence to: Anna S. Levin, Rua Banibas 618, 05460-010 São Paulo, SP, Brasil. Phone/fax: 55.11.2661-7066. E-mail: gcih.adm@hc.fm.usp.br 


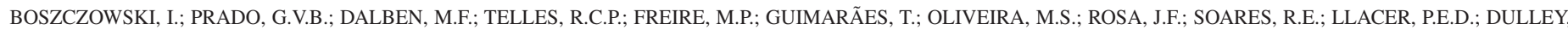
F.L.; COSTA, S.F. \& LEVIN, A.S. - Polyclonal outbreak of bloodstream infections caused by Burkholderia cepacia complex in Hematology and Bone Marrow Transplant outpatient units. Rev. Inst. Med. Trop. Sao Paulo, 56(1): 71-6, 2014.

following factors were recorded: sex; age; underlying diseases; the presence and the type of central venous catheter (CVC), insertion date, type of dressing used (gauze or transparent), type of antiseptic used during CVC handling; the use of IV medications, including heparin, and of blood products; the use of chemotherapy; dates of the last three uses of the CVC before the first positive culture and the healthcare workers who had cared for each patient. Cases were treated with meropenem.

Infection Control Measures: Two visits on different days and meetings with all the staff of the affected units were held in order to evaluate practices in infection control and managing of infusion therapy. The main findings were the following:

- Multi-dose heparin, methylprednisolone and saline solution for intravenous infusion were routinely used. The containers and vials were not left with needles inserted in them but it was not clear how many patients used each vial nor was there a control of when they should be discarded. These multi-use items were placed on the shared counter;

- Nurses frequently prepared prescribed medications in the morning for use during the whole day in order to "save time";

- Syringes with aspirated solution without identification (patient name, type of solution or time of preparation) were placed on the counter and used for flushing catheters during the day;

- There was no exclusive sink inside the room used for the preparation of infusion therapy;

- There were empty vials of alcohol-based solution for hand hygiene;

- There was no evidence of systematic cleaning of the laminar flow cabinet and the refrigerator used for medication storage as well as controls of refrigerator temperature;

- There was no evidence of systematic cleaning of surfaces with a disinfectant product.

Based on these findings, the following control measures were implemented:

- Heparin, methylprednisolone and hydrocortisone vials were defined for a single patient and each vial received a label with the patient's name;

- Syringes with medication were left in the laminar flow cabinet until the moment of administration to patient and medication other than chemotherapy was to be prepared immediately before administration;

- Batches of antiseptic chlorhexidine (soap and alcohol-based) were replaced;

- Cleaning of laminar flow cabinet and control of temperature of refrigerators were reinforced;

- Cleaning of the areas in which medication was prepared with a chlorine-based product was reinforced;

- Hand hygiene was emphasized and the number of alcohol rub dispensers in the units was increased;

- Blood cultures of all patients with a CVC that had been handled in the affected units during the outbreak period were collected;

- Lock with ceftazidime for all long-term CVCs was instituted;

- Active surveillance for new cases was implemented.

Microbiologic study: The following items were cultured between February 21 and 28:

- Swabs from taps, sink drains, counters, laminar flow cabinet and healthcare workers hands (nurses, pharmacists) and other patients in direct contact with cases. Swabs were plated on BCSA (Burkholderia cepacia selective agar) and then inoculated in a $600,000 \mathrm{UI} / \mathrm{L}$ polymyxin $\mathrm{B}$, vancomycin $2.5 \mathrm{mg} / \mathrm{L}$ and gentamicin $10 \mathrm{mg} / \mathrm{L} \mathrm{BHI}$ broth (brain heart infusion). They were incubated at $10-32^{\circ} \mathrm{C}$ up to seven days. Growing colonies were then submitted to Gram staining. Glucose fermenting was tested by OF (oxidation-fermentation) open and closed tubes and oxidase tests. After non-fermenting confirmation, biochemical tests for B. cepacia complex identification were performed: OF-glucose, OF-maltose, OF-xylose, OF-lactose, OF-sucrose and/or lysine decarboxylation;

- Water samples were collected (1 L of both cold and hot water) in sterile containers. Samples were divided into two aliquots of 500 $\mathrm{mL}$ each and filtered in an acetate cellulose membrane with $0.25 \mu \mathrm{m}$ pores and then plated on BCSA and MacConkey agar.

The hospital's clinical microbiology laboratory used an automatized system for identification (Vitek, bioMerrieux). Reidentification of $B$. cepacia isolates was performed using the phenotypic method API ${ }^{\circledR} 20$ NE (bioMérieux SA, Lyon, France). The isolates that were phenotypically defined as belonging to the B. cepacia complex were submitted to molecular identification using multiplex polymerase chain reaction with the primers and technique as described elsewhere ${ }^{12}$. The fur gene was amplified for various strains using primers JD490 and JD491 and the DNA sequences were determined by direct sequencing from the amplicons using the MegaBACE 1000 DNA Sequencer. The sequences were analyzed using the software Sequence Analyzer with the Base Caller Cimarron 3.12 and compared with those in GenBank (www.ncbi.nlm. nih.gov). This method can identify the following species: $B$. cepacia, $B$. multivorans, B. cenocepacia, B. dolosa, B. vietnamiensis, B. ambifaria, B. stabilis, B. antina, Bcc group $\mathrm{K}$ and $B$. pyrrocinia. Isolates were typed using pulsed-field gel electrophoresis (PFGE) ${ }^{18}$ using the restriction enzyme SpeI and interpreted according to criteria by TENOVER et al. ${ }^{20}$. Minimum inhibitory concentrations (MIC) for ceftazidime, meropenem, minocycline, levofloxacin and sulfamethoxazole-trimethoprim were determined and interpreted using the agar microdilution technique ${ }^{4}$.

\section{RESULTS}

Based on the case definition, 27 patients were identified but we could only retrieve clinical information pertaining to 24 due to failure to retrieve complete records for three patients. Revision of the infection control database could not identify any cases of bacteremia by B. cepacia from January through December 2007 in our hospital (Fig. 1).

The main symptoms of cases were fever, present in 21 (88\%) patients, chills in 14 (58\%), coughing in two and hypotension and septic shock in one patient each (Table 1). Ten patients had their CVC used on February 11 and/or 12 and, in nine of these patients, this had been their last CVC use before the positive blood culture. None of the HCWs could be directly implicated as the source of the outbreak, especially because each HCW only worked in one of the affected units (Fig. 2).

Two patients were hospitalized in Hematology inpatient unit when they acquired the Burkholderia infection. However, they were included in the outbreak because they received chemotherapy prepared in the outpatient unit. Fifteen patients $(56 \%)$ had their catheters removed, on average 17.8 days after the positive blood culture (range: 1-70, median: 14). Eight patients $(30 \%)$ were hospitalized, and one patient died within thirty days after the positive culture of causes not related to the infection. 


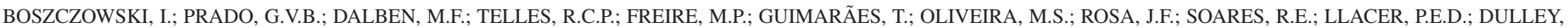

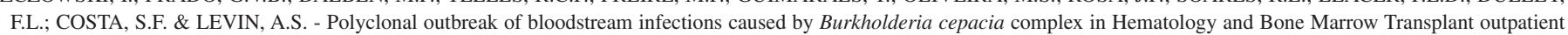
units. Rev. Inst. Med. Trop. Sao Paulo, 56(1): 71-6, 2014.

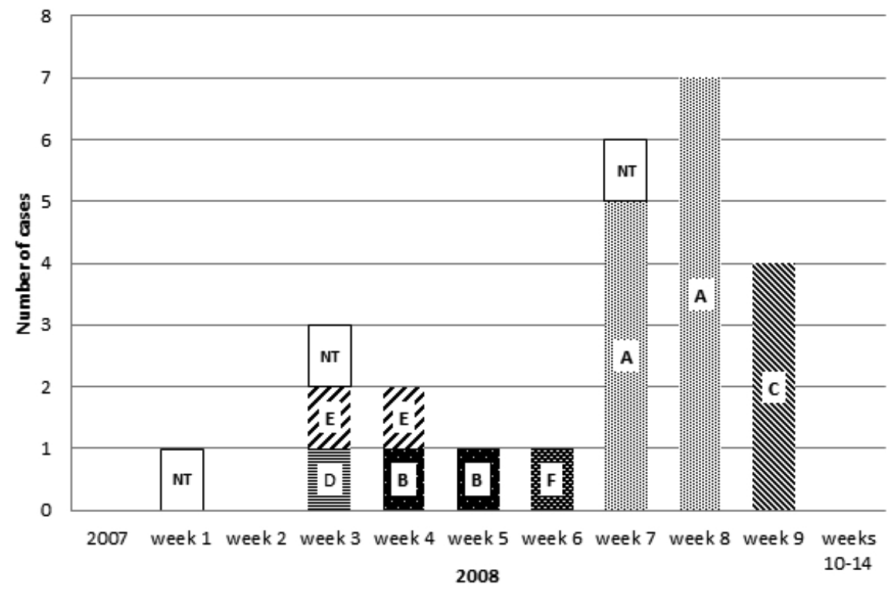

Fig. 1 - Distribution of cases over time and molecular types during an outbreak of bloodstream infections caused by Burkholderia cepacia in two outpatient units (Hematology and Bone Marrow Transplant). Hospital das Clínicas, University of São Paulo, Brazil. 2007 to March, 2008. (Only the first isolate from each patient is depicted).

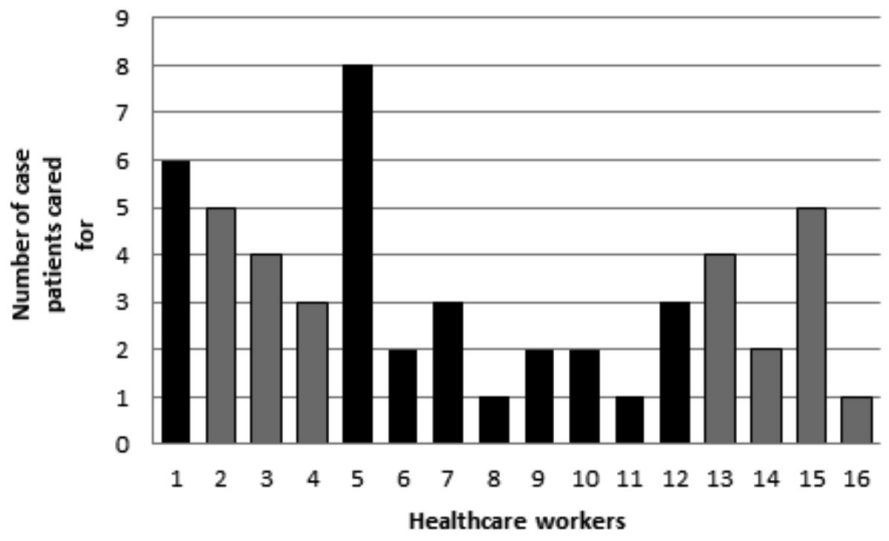

Fig. 2 - Number of case patients cared for by each healthcare worker during an outbreak of bloodstream infections caused by Burkholderia cepacia in two outpatient units. (Hematology Unit: black bars; Bone Marrow Transplant Unit: grey bars). Hospital das Clínicas, University of São Paulo, Brazil. January-February, 2008.

After the implementation of the control measures no new cases occurred.

None of the environmental cultures or HCW hand swabs was positive for Burkholderia cepacia complex.

Twenty-three isolates from 21 patients were available for molecular identification and typing and for determination of MICs. 14 isolates were identified as $B$. multivorans and six belonged to the B. cepacia complex but could not be identified to the species level. One isolate did not belong to the $B$. cepacia complex, and could not be completely identified. The distribution of molecular types based on PFGE can be seen in Figure 1. PFGE types were named A through F. The predominant type, called A and identified as B. multivorans, was only present starting on February 12, 2008 and all infections occurred in patients belonging to the Hematology Unit. PFGE type D was $B$. cenocepacia and type $\mathrm{E}$ was $B$. multivorans. Isolates PFGE types $\mathrm{B}$ and $\mathrm{C}$ were the $B$. cepacia complex ones with
Table 1

Characteristics of 24 patients involved in an outbreak of bloodstream infections caused by Burkholderia cepacia in two outpatient units (Hematology and Bone Marrow Transplant). Hospital das Clínicas, University of São Paulo, Brazil. January-February, 2008

\begin{tabular}{lc}
\hline Characteristics & \\
\hline Male sex & $10(42 \%)$ \\
\hline Age (years) & $34(16.4)$ \\
$\quad$ Mean (SD) & $30(2-64)$ \\
Median (range) & \\
\hline Outpatient unit & $13(54 \%)$ \\
Hematology & $11(46 \%)$ \\
Bone marrow transplant & \\
\hline Underlying disease & $8(33 \%)$ \\
Hodgkin's lymphoma & $7(29 \%)$ \\
Non-Hodgkin's lymphoma & $3(13 \%)$ \\
Aplastic anemia & $2(8 \%)$ \\
Chronic myelocytic leukemia & 1 \\
Myelofibrosis & 1 \\
Acute myelocytic leukemia & 1 \\
Acute lymphocytic leukemia & 1 \\
Primitive neuroectodermal tumor &
\end{tabular}

\section{Type of CVC}

Totally implanted

Partially implanted

Type of dressing used on CVC site

Transparent film

$17(71 \%)$

Gauze

$7(29 \%)$

\begin{tabular}{lc}
\hline Use of chlorhexidine at CVC site & $24(100 \%)$ \\
\hline Under chemotherapy & $8(33 \%)$ \\
\hline Products administered through CVC & \\
Heparin & $24(100 \%)$ \\
Dexamethasone & $7(29 \%)$ \\
Teicoplanin & $7(29 \%)$ \\
Ondansetron & $6(25 \%)$ \\
Cefepime & $5(21 \%)$ \\
Dipirone & $5(21 \%)$ \\
Meropenem & $5(21 \%)$ \\
Filgrastim & $4(17 \%)$ \\
Ceftriaxone & $3(13 \%)$ \\
Platelet concentrate & $3(13 \%)$ \\
Fluconazole & $3(13 \%)$ \\
Levofloxacin & $3(13 \%)$ \\
Acyclovir & 2 \\
Red blood cell concentrate & 2 \\
Dimenidrate & 2 \\
\hline CVC was used on February 11 and/or 12,2008 & $10(42 \%)$ \\
\hline
\end{tabular}

CVC was used on February 11 and/or 12, 2008

$10(42 \%)$

Days between CVC insertion and positive blood culture Mean (SD) Median (range)

Days between last use of CVC and positive blood culture ${ }^{2}$ Mean (SD)

Median (range)

SD: standard deviation; CVC: central venous catheter; ${ }^{1}$ data available for 20 patients; ${ }^{2}$ data available for 21 patients. 


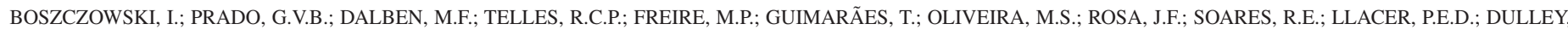
F.L.; COSTA, S.F. \& LEVIN, A.S. - Polyclonal outbreak of bloodstream infections caused by Burkholderia cepacia complex in Hematology and Bone Marrow Transplant outpatient units. Rev. Inst. Med. Trop. Sao Paulo, 56(1): 71-6, 2014.

species level not identified. They only occurred during the last three days of the outbreak. The isolate presenting PFGE type $\mathrm{F}$ was the one that did not belong to the B. cepacia complex.

Two patients presented more than one isolate. One patient had two different species, initially $B$. multivorans (PFGE type E), and then $B$. cenocepacia 25 days after the first episode (PFGE type D). The other patient had two isolates with different PFGE types (B and E) that were identified from cultures collected five days apart.

$\mathrm{MIC}_{50}$ was $4 \mu \mathrm{g} / \mathrm{mL} ; 1 ; 2 ; 2$ and $1 \mu \mathrm{g} / \mathrm{mL}$ for ceftazidime, levofloxacin; minocycline, meropenem and sulfamethoxazole/ trimethoprim, respectively. $\mathrm{MIC}_{90}$ was $8 \mu \mathrm{g} / \mathrm{mL} ; 16 ; 8 ; 4$; and $8 \mu \mathrm{g} / \mathrm{mL}$ respectively for the same antimicrobial drugs.

\section{DISCUSSION}

Our study describes an outbreak of Burkholderia cepacia complex bloodstream infections in Hematologic and Bone Marrow Transplant outpatient units with multiple clones and species. No other cases of Bcc infections were diagnosed in the entire hospital during the outbreak period or in the previous year, fitting the definition of outbreak and strongly pointing to a localized problem in the two affected outpatient units. Although evidence points to a common source, this could not be completely proven and the fact that there are multiple clones and species makes interpretation difficult. During the entire outbreak period, inadequate practices in preparation and storage of intravenous medication probably favored contamination leading to bloodstream infections. This hypothesis is reinforced by the fact that two case patients were hospitalized and their only epidemiologic link to the other cases was that they had received medication prepared in the outpatient area. No healthcare worker could be directly implicated as the source of the outbreak especially because, although the unit shared areas, each worker belonged strictly to one of the units and there was no sharing of healthcare workers between the units.

We hypothesized that two distinct events took place. There seems to clearly have been a contamination by $B$. multivorans (molecular type A) and probably the source was the use of intravenous drugs or solutions prepared from multi-dose vials in the Hematology unit. Although we could not definitely demonstrate a common source of $B$. multivorans, the case distribution and the fact that ten patients had had their CVC manipulated on February 11 and/or 12 makes it probable that contaminated solution was administered. As there were no cases in other units of the hospital, contamination during industrial production is improbable and it must have occurred during manipulation of the multi-dose vials. Solutions under suspicion were saline used for central catheter flushing and heparin. All twelve patients who presented with type A-B. multivorans in blood cultures had received heparin through their catheters and it is not possible to ascertain whether they received saline from a multi-dose vial as this was not routinely registered in the patients' records. Saline flushing of the CVC was a common practice in the units. Among the recommendations on good practices in intravenous therapy, multi-dose vials should be avoided and intravenous solutions should not be stored for long periods of time after preparation. To our knowledge there have not been reports of outbreaks of $B$. multivorans due to the contamination of multi-dose vials of intravenous medication although reports of such contamination by other agents have been reported. In an outbreak of CVC associated bloodstream infection by B. cepacia and Myroides odoratus, commercial ampoules of sterile water intrinsically contaminated were found to be the common source ${ }^{7}$. The contamination of Ringer lactate solution used as multiple-dose vial to flush peripheral venous catheters was the cause of an outbreak of bloodstream infections by clonal B. cepacia ${ }^{6}$. The contamination of a heparin flush solution used for catheters in an oncology unit caused a B. cepacia (formerly Pseudomonas cepacia) outbreak already back in $1991^{21}$. In a systematic review of HAI related to contaminated substances ${ }^{23}$, Bcc ranked first as contaminating pathogen in substances other than blood.

The contamination of multi-dose medication does not fully explain the outbreak. Although most outbreaks of Bcc described have been clonal $1^{6,10,11}$, an outbreak caused by contaminated bromopride in 2006 was shown to be polyclonal ${ }^{14}$. Bcc are bacteria largely present in the natural environment, such as soil, water and rhizosphere, which is the environment adjacent to the roots of plants ${ }^{22}$, in which different species may co-exist. Most species belonging to Bcc have also been shown to produce biofilm ${ }^{5}$ which may be important in the pathogenesis of human disease. Patients with cystic fibrosis have been described to carry different species of $\mathrm{Bcc}^{3}$. Thus it is possible that in the hospital, environmental contamination by Bcc be polyclonal, thus causing polyclonal infections. It is possible that a contaminated environmental source, such as the laminar flow cabinet, was involved in the outbreak. This cabinet was the only common feature between the two units and inadequate maintenance of the cabinets was observed. It is possible that biofilm formed within the cabinet contained multiple species of Burkholderia which would explain the two cases with $B$. multivorans found in BMT patients that did not belong to the same clone, B. cenocepacia and the cases caused by unidentified species of Burkholderia. Unfortunately, this is only a hypothesis as cultures obtained from the cabinet were negative. Measures to improve cabinet maintenance and cleaning were implemented among others to control the outbreak.

Identification to the species level of Burkholderia cepacia poses a problem to the clinical laboratory because phenotypical tests are not reliable to differentiate between species within Bcc. Reference laboratories are usually needed for identification that depends on molecular techniques. Thus, managing clinical and epidemiological issues, such as outbreaks, at the point of care is a problem. New methods that allow the search for species-specific biomarkers such as matrixassisted laser desorption ionization-time of flight mass spectrometry (MALDI-TOF MS) are promising for $\mathrm{Bcc}^{16}$. Molecular typing such as PFGE, used in our outbreak, matched the results of species identification. However typing was useless to explain the outbreak. In fact it could even have been misleading as finding multiple clones may have weakened the hypothesis of an outbreak.

A limitation of our study was that medications from multi-dose vials were not available for culturing and that the laminar flow cabinet was not entirely dismantled for culturing.

In summary, the outbreak of bloodstream infections caused by Burkholderia spp. was interrupted by reinforcing good practices, probably eliminating the contamination of multi-dose vials and the common source. The finding of different species was an original feature of this outbreak. 


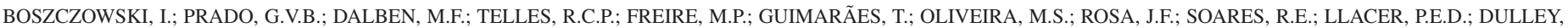

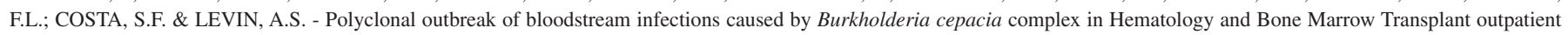
units. Rev. Inst. Med. Trop. Sao Paulo, 56(1): 71-6, 2014.

\section{RESUMO}

\section{Surto policlonal de infecção de corrente sanguínea causada pelo complexo Burkholderia cepacia em unidades de hospital-dia de hematologia e transplante de medula óssea}

O objetivo foi descrever um surto de infecções da corrente sanguínea por complexo B. cepacia (Bcc) nos ambulatórios de hematologia e transplante de medula óssea. Métodos: Em 15/02/2008, um surto de Bcc foi suspeitado. 24 casos foram identificados. Os dados demográficos e clínicos foram avaliados. Mãos de profissionais da saúde e ambiente foram cultivadas. Espécies foram determinadas e tipadas. Reforço da higiene das mãos, cuidados com cateteres, terapia de infusão e manutenção da câmara de fluxo laminar foram realizadas. 16 profissionais de saúde (PS) diferentes manipularam os cateteres. Heparina multidoses e soro eram preparadas em um balcão comum a ambas as unidades. Resultados: 14 pacientes tiveram B. multivorans (um paciente teve também B. cenopacia), 6 Bcc não-multivorans e um teve um agente não pertencente a Bcc. Clone A de B. multivorans ocorreu em 12 pacientes (da Hematologia), em 10 o cateter havia sido utilizado nos dias 11 ou 12 de fevereiro. Culturas ambientais e de PS foram negativos. Todos os pacientes foram tratados com meropenem e selo de ceftazidima. Oito pacientes $(30 \%)$ foram hospitalizados. Não ocorreram mortes. Após as medidas de controle, nenhum novo caso ocorreu. Conclusões: Este surto policlonal pode ser explicado por uma fonte comum contendo várias espécies de Bcc, talvez a câmara de fluxo laminar comum a ambas as unidades. Pode ter havido contaminação por B. multivorans (clone A) de frascos multi-dose.

\section{FUNDING}

This study was funded by Hospital das Clínicas, University of São Paulo, Brazil. RCPT received a student grant from Fundação de Auxílio à Pesquisa do Estado de São Paulo (FAPESP 2010/09714-8)

\section{CONFLICTS OF INTEREST}

The authors declare no conflicts of interest involving this study.

\section{REFERENCES}

1. Abe K, D'Angelo MT, Sunenshine R, Noble-Wang J, Cope J, Jensen B, et al. Outbreak of Burkholderia cepacia bloodstream infection at an outpatient hematology and oncology practice. Infect Control Hosp Epidemiol. 2007;28:1311-3.

2. Alvarez-Lerma F, Maull E, Terradas R, Segura C, Planells I, Coll P, et al. Moisturizing body milk as a reservoir of Burkholderia cepacia: outbreak of nosocomial infection in a multidisciplinary intensive care unit. Crit Care. 2008;12:R10.

3. Carvalho GMV, Carvalho APD, Folescu TW, Higa L, Teixeira LM, Plotkowski MCM, et al. Transient isolation of Burkholderia multivorans and Burkholderia cenocepacia from a Brazilian cystic fibrosis patient chronically colonized with Burkholderia vietnamiensis. J Cystic Fibrosis. 2005;4:267-70.

4. Clinical and Laboratory Standards Institute. Performance standards for antimicrobial susceptibility testing: nineteenth informational supplement. CLSI document M100 - S20. Wayne: Clinical and Laboratory Standards Institute; 2010.

5. Conway BA, Venu V, Speert DP. Biofilm formation and acyl homoserine lactone production in the Burkholderia cepacia complex. J Bacteriol. 2002;184:5678-85.
6. De Smet B, Veng C, Kruy L, Kham C, van Griensven J, Peeters C, et al. Outbreak of Burkholderia cepacia bloodstream infections traced to the use of Ringer lactate solution as multiple-dose vial for catheter flushing, Phnom Penh, Cambodia. Clin Microbiol Infect. 2013;19:832-7.

7. Douce RW, Zurita J, Sanchez O, Cardenas Aldaz P. Investigation of an outbreak of central venous catheter-associated bloodstream infection due to contaminated water. Infect Control Hosp Epidemiol. 2008;29:364-6.

8. Drevinek P, Vosahlikova S, Dedeckova K, Cinek O, Mahenthiralingam E. Direct cultureindependent strain typing of Burkholderia cepacia complex in sputum samples from patients with cystic fibrosis. J Clin Microbiol. 2010;48:1888-91.

9. Heo ST, Kim SJ, Jeong YG, Bae IG, Jin JS, Lee JC. Hospital outbreak of Burkholderia stabilis bacteremia related to contaminated chlorhexidine in hematological malignancy patients with indwelling catheters. J Hosp Infect. 2008;70:241-5.

10. Lo Cascio G, Bonora MG, Zorzi A, Mortani E, Tessitore N, Loschiavo C, et al. A napkinassociated outbreak of Burkholderia cenocepacia bacteraemia in haemodialysis patients. J Hosp Infect. 2006;64:56-62.

11. Lucero CA, Cohen AL, Trevino I, Rupp AH, Harris M, Forkan-Kelly S, et al. Outbreak of Burkholderia cepacia complex among ventilated pediatric patients linked to hospital sinks. Am J Infect Control. 2011;39:775-8.

12. Lynch KH, Dennis JJ. Development of a species-specific fur gene-based method for identification of the Burkholderia cepacia complex. J Clin Microbiol. 2008;46:447-55.

13. Martin M, Christiansen B, Caspari G, Hogardt M, von Thomsen AJ, Ott E, et al. Hospital-wide outbreak of Burkholderia contaminans caused by prefabricated moist washcloths. J Hosp Infect. 2011;77:267-70.

14. Martins IS, Pellegrino FL, Freitas A, Santos M da S, Ferraiuoli GI, Vasques MR, et al. Case-crossover study of Burkholderia cepacia complex bloodstream infection associated with contaminated intravenous bromopride. Infect Control Hosp Epidemiol. 2010;31:516-21.

15. Memish ZA, Stephens G, Balkhy HH, Cunningham G, Francis C, Poff G. Outbreak of Burkholderia cepacia bacteremia in immunocompetent children caused by contaminated nebulized salbutamol in Saudi Arabia. Am J Infect Control. 2009;37:431-2.

16. Mott T, Soler M, Grigsby S, Medley R, Whitlock GC. Identification of potential diagnostic markers among Burkholderia cenocepacia and B. multivorans supernatants. J Clin Microbiol. 2010;48:4186-92.

17. Pegues DA, Carson LA, Anderson RL, Norgard MJ, Argent TA, Jarvis WR, et al. Outbreak of Pseudomonas cepacia bacteremia in oncology patients. Clin Infect Dis. 1993;16:407-11

18. Pfaller MA, Hollis RJ, Sader HS. Molecular biology - PFGE analysis of chromosomal restriction fragments. In: Isenberg $\mathrm{HD}$, editor. Clinical microbiology procedures handbook. Washington: ASM Press; 1992. p. 10.5.c.1-10.5.c.11.

19. Snyder JW, Munier GK, Johnson CL. Direct comparison of the BD Phoenix system with the MicroScanWalkAway system for identification and antimicrobial susceptibility testing of Enterobacteriaceae and nonfermentative Gram-negative organisms. J Clin Microbiol. 2008;46:2327-33.

20. Tenover FC, Arbeit RD, Goering RV, Mickelsen PA, Murray BE, Persing DH, et al. Interpreting chromosomal DNA restriction patterns produced by pulsed-field gel electrophoresis: criteria for bacterial strains typing. J Clin Microbiol. 1995;33:2233-9.

21. Vanlaere E, Baldwin A, Gevers D, Henry D, De Brandt E, LiPuma JJ, et al. Taxon K, a complex within the Burkholderia cepacia complex, comprises at least two novel species, Burkholderia contaminans sp. nov. and Burkholderia lata sp. nov. Int J Syst Evol Microbiol. 2009;59:102-11. 
BOSZCZOWSKI, I.; PRADO, G.V.B.; DALBEN, M.F.; TELLES, R.C.P.; FREIRE, M.P.; GUIMARÃES, T.; OLIVEIRA, M.S.; ROSA, J.F.; SOARES, R.E.; LLACER, P.E.D.; DULLEY, F.L.; COSTA, S.F. \& LEVIN, A.S. - Polyclonal outbreak of bloodstream infections caused by Burkholderia cepacia complex in Hematology and Bone Marrow Transplant outpatient units. Rev. Inst. Med. Trop. Sao Paulo, 56(1): 71-6, 2014

22. Vial L, Chapalain A, Groleau M-C, Déziel E. The various lifestyles of the Burkholderia cepacia complex species: a tribute to adaptation. Environm Microbiol. 2011;13:1-12.

23. Vonberg RP, Gastmeier P. Hospital-acquired infections related to contaminated substances. J Hosp Infect. 2007;65:15-23.

24. Yang CJ, Chen TC, Liao LF, Ma L, Wang CS, Lu PL, et al. Nosocomial outbreak of two strains of Burkholderia cepacia caused by contaminated heparin. J Hosp Infect. 2008;69:398-400.
25. Zbinden A, Böttger EC, Bosshard PP, Zbinden R. Evaluation of the colorimetric VITEK 2 card for identification of Gram-negative nonfermentative rods: comparison to $16 \mathrm{~S}$ rRNA gene sequencing. J Clin Microbiol. 2007;45:2270-3

Received: 4 March 2013

Accepted: 23 May 2013 